\title{
Numerical Analysis of Chemical Heat Storage Units for Waste Heat Recovery in Steel Making Processes
}

\author{
Massimiliano ZAMENGO, ${ }^{*}$ Junichi RYU and Yukitaka KATO* \\ Research Laboratory for Nuclear Reactors, Tokyo Institute of Technology, 2-12-1-N1-22, Ookayama, Meguro-ku, Tokyo, 152- \\ 8550 Japan.
}

(Received on May 31, 2014; accepted on August 20, 2014)

\begin{abstract}
Magnesium oxide/water/magnesium hydroxide $\left(\mathrm{MgO} / \mathrm{H}_{2} \mathrm{O} / \mathrm{Mg}(\mathrm{OH})_{2}\right)$ heat storage system using a composite material mixed with $\mathrm{Mg}(\mathrm{OH})_{2}$ and expanded graphite $(\mathrm{EG})$, named as $\mathrm{EM}$, was discussed experimentally and numerically. Thermal performance of EM tablet of $10 \mathrm{~mm}$ diameter and $7 \mathrm{~mm}$ thickness was evaluated by packed bed reactor experiments. Thermal performance of a packed bed of pure $\mathrm{Mg}(\mathrm{OH})_{2}$ pellets (diameter of pellet of $2 \mathrm{~mm}$ and 5-10 $\mathrm{mm}$ length) was compared with one of EM in the same experimental reactor. It was observed that the higher effective thermal conductivity of the bed of EM tablets contributed on enhancing the heat storage performance of the packed bed reactor. The effect of thermal conductivity enhancement of thermochemical heat storage materials was discussed numerically. The numerical model was utilized for a preliminary investigation on the behavior of a larger system, made of bundles of chemical heat storage units (CHSU), designed as pipes (length of $2 \mathrm{~m}$ ) containing a packed bed of CHS material. It was shown that CHSU charged with EM tablets was capable to be utilized for recovery waste heat from the cooling down process of continuous casting of steel slabs.
\end{abstract}

KEY WORDS: thermochemical energy storage; magnesium hydroxide; expanded graphite; thermal conductivity enhancement; waste heat recovery; chemical heat storage unit.

\section{Introduction}

For a sustainable and energy efficient production, steel makers are doing efforts to implement waste heat recovery system into the steel production lines. When cooling down the products, for example steel slabs, large amounts of heat at different temperatures are released. One possibility is to convert heat directly into electricity using thermoelectric effect. $^{1,2)}$ At temperatures lower than $300^{\circ} \mathrm{C}$ heat can be recovered by sensible and latent heat storage technologies. $^{3,4)}$ On the other hand, these storage technologies present large heat losses. Efficient utilization of the hightemperature heat would be one of important way for an improvement of energy efficiency of high-temperature processes. Magnesium oxide/water/magnesium hydroxide $\left(\mathrm{MgO} / \mathrm{H}_{2} \mathrm{O} / \mathrm{Mg}(\mathrm{OH})_{2}\right)$ thermochemical heat storage is one of candidate reaction system for heat recovery at $400{ }^{\circ} \mathrm{C}^{5 \text { ) }}$

$\mathrm{MgO}(\mathrm{s})+\mathrm{H}_{2} \mathrm{O}(\mathrm{g}) \leftrightarrow \mathrm{Mg}(\mathrm{OH})_{2}(\mathrm{~s}), \Delta H^{\circ}=-81.0 \mathrm{~kJ} \mathrm{~mol}^{-1}$

Figure 1(a) shows thermochemical heat storage material pellet using a pure- $\mathrm{Mg}(\mathrm{OH})_{2}(\mathrm{MH}-\mathrm{V} 05 \mathrm{G}$, Ube Material, Japan, developed by Kato et al. $\left.{ }^{6)}\right)$. Differently from sensible and latent heat recovery technologies, chemical heat storage allows storing heat for longer time, as chemical heat can be released only when the reaction is conducted by an operator.

\footnotetext{
* Corresponding author: E-mail: yukitaka@nr.titech.ac.jp, zamengo.m.aa@m.titech.ac.jp
}

DOI: http://dx.doi.org/10.2355/isijinternational.55.473
For using latent heat storage with molten salt at temperature of approx. $350^{\circ} \mathrm{C}$, there exists some candidate materials like lithium nitrite, $\mathrm{LiNO}_{2}$, sodium nitrate, $\mathrm{NaNO}_{3}$ or potassium nitrate, $\mathrm{KNO}_{3}$. Their latent heats of fusion and melting temperature are respectively $363 \mathrm{~kJ} / \mathrm{kg} @ 252^{\circ} \mathrm{C}, 173 \mathrm{~kJ} / \mathrm{kg} @$ $304^{\circ} \mathrm{C}$ and $96.6 \mathrm{~kJ} / \mathrm{kg} @ 334^{\circ} \mathrm{C}$, respectively. ${ }^{7)}$ In case of chemical heat storage with $\mathrm{Mg}(\mathrm{OH})_{2}$, the enthalpy change of reaction is $1390 \mathrm{~kJ} / \mathrm{kg}$, which results 4-14 times higher of the previous heats of fusion.

Although the $\mathrm{Mg}(\mathrm{OH})_{2}$ pellet has high reactivity, thermal conductivity enhancement of material is important for efficient heat exchange. The packed bed of $\mathrm{Mg}(\mathrm{OH})_{2}$ pellets is characterized by a low effective thermal conductivity, around $0.2 \mathrm{~W} \mathrm{~m}^{-1} \mathrm{~K}^{-1}$. Expanded graphite (EG) is a good candidate for thermal conductivity enhancement. $\mathrm{Mg}(\mathrm{OH})_{2}$ composite mixed with EG, named as EM, was developed in previous works. ${ }^{8}$ In comparison with pure- $\mathrm{Mg}(\mathrm{OH})_{2}, \mathrm{EM}$ has mold-ability property, which means capability of being shaped easily into a specific figure by compaction in a mold. Fig. 1(b) shows tablet figure EM which has mixing mass ratio between $\mathrm{Mg}(\mathrm{OH})_{2}$ and $\mathrm{EG}$ of $8: 1$. Such mixing ratio showed optimal performances among others. ${ }^{9)}$ Measurements of thermal conductivity of packed bed of EM tablets showed higher effective thermal conductivity $\left(0.45-0.55 \mathrm{~W} \mathrm{~m}^{-1} \mathrm{~K}^{-1}\right)$.

This study evaluated thermal performance of EM tablets bed by packed bed reactor experiments. Then, the effect of thermal conductivity enhancement of thermochemical heat storage materials was discussed numerically. A numerical model was utilized for a preliminary investigation on the 


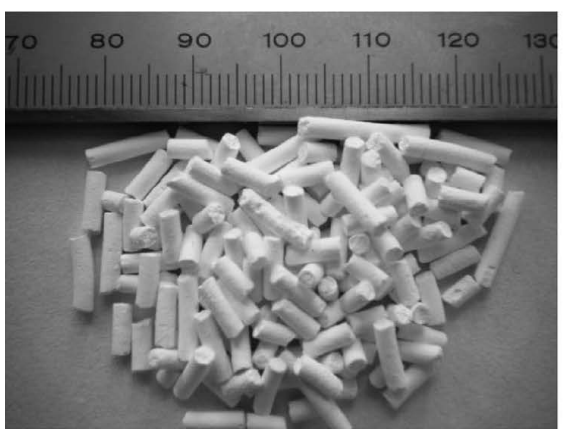

(a)

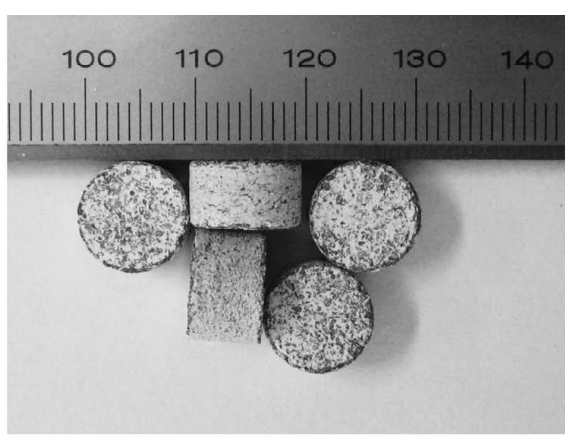

(b)

Fig. 1. Reaction materials: (a) pure- $\mathrm{Mg}(\mathrm{OH})_{2}$ pellets, (b) EM tablets.

behavior of a larger system, made of bundles of chemical heat storage units (CHSU), designed to be utilized for waste heat recovery from the cooling down process of continuous casting of steel slabs.

\section{Material Preparation for the Packed Bed Reactor Experiments}

\subsection{Preparation Method of EM Composite}

EG and crushed pure- $\mathrm{Mg}(\mathrm{OH})_{2}$ pellets $(\phi=1.9 \mathrm{~mm} \times$ length 5-10 mm) in Fig. 1(a) were used as precursors for the preparation of EM composite. EG was obtained from graphite flakes after thermal treatment $\left(700^{\circ} \mathrm{C}\right.$ for $\left.10 \mathrm{~min}\right)$ in an electric muffle furnace under atmospheric conditions. The EM composite was prepared as follows:

1. The $\mathrm{Mg}(\mathrm{OH})_{2}$ powder and EG in mass mixing ratio of $8: 1$ were placed in a glass dish (diameter $10 \mathrm{~cm}$ ); then, purified water was added (approx. $30 \mathrm{ml} / \mathrm{g}$ of EG) to the powder mixture, and the resulting suspension was mixed gently using a spatula.

2. After obtaining a homogeneous mixture, the glass dish was placed in a furnace for approximately $15 \mathrm{~min}$ at $120^{\circ} \mathrm{C}$ under atmospheric conditions. A homogeneous mixture of $\mathrm{Mg}(\mathrm{OH})_{2}$ and EG (EM) was obtained by re-mixing it with the spatula before the complete evaporation of water. The mixture was kept in the furnace for 12 hours until it resulted completely dry.

3. After removal from the furnace, the EM composite was compressed into tablets using a stainless steel mold set. The EM tablets had a diameter of $10.1 \mathrm{~mm}$ and a thickness $(l)$ of $6.1 \mathrm{~mm}$.

The value of mass mixing ratio $\psi[-]$ was determined by the following expression:

$$
\psi=\frac{m_{M g(O H)_{2}}}{m_{E G}}
$$

where $m_{\mathrm{Mg}(\mathrm{OH})_{2}}$ and $m_{\mathrm{EG}}$ are respectively the mass of $\mathrm{Mg}(\mathrm{OH})_{2}$ and EG used for the preparation of EM.

\subsection{Experimental Packed Bed Reactor}

Pure- $\mathrm{Mg}(\mathrm{OH})_{2}$ pellets and EM tablets were examined by using an experimental packed bed reactor apparatus. ${ }^{10)}$ The packed bed reactor utilized for the experiment is shown in Fig. 2. The cylindrical reactor, made of stainless-steel, had a diameter of $48 \mathrm{~mm}$ and depth of $48 \mathrm{~mm}$, while the steel thickness was $2 \mathrm{~mm}$.

K-type thermocouples were used for temperature mea-

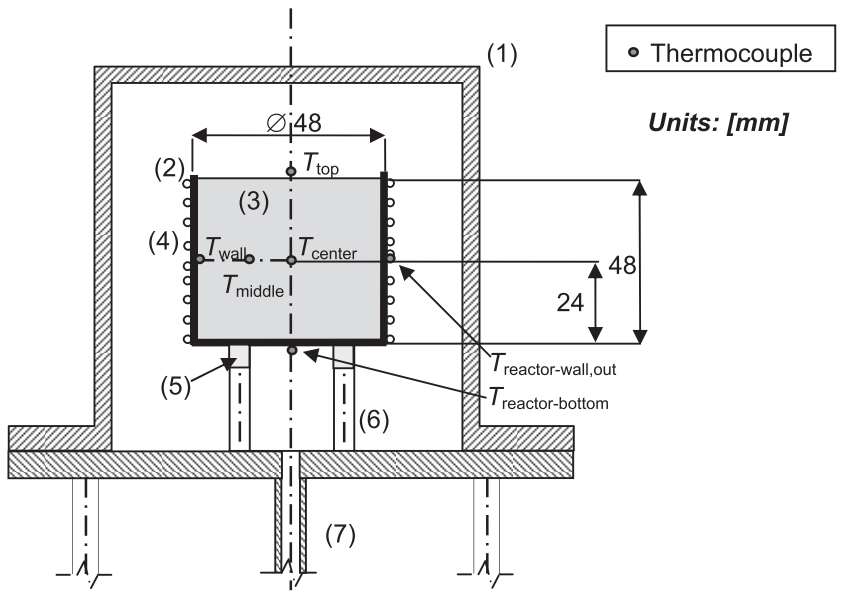

Fig. 2. Experimental packed bed reactor: (1) reaction chamber, (2) packed bed reactor, (3) reactant bed, (4) Sheath heater, (5) Insulator, (6) reactor stem (7) water vapor outlet/inlet.

surement of the locations showed in the Fig. 2. The packed bed materials were charged from the top. During the reactions, water vapor moved outside or inside of the bed from the top surface of the packed bed. Pure- $\mathrm{Mg}(\mathrm{OH})_{2}$ pellets were charged randomly in the bed, while the EM tablets were piled in the bed: this was necessary because in a previous work ${ }^{9)}$ EM tablets were charged randomly in the packed bed, but the amount of $\mathrm{Mg}(\mathrm{OH})_{2}$ charged was less than the in the bed of $\mathrm{Mg}(\mathrm{OH})_{2}$ pellets. Therefore, the size of the EM tablets and the tidy pile arrangement were selected in order to be able to load in the reactor the same amount of $\mathrm{Mg}(\mathrm{OH})_{2}$ as of the pure- $\mathrm{Mg}(\mathrm{OH})_{2}$ pellets (approx. $44 \mathrm{~g}$ ) In this way, the heat storage per unit volume would be the same and it results easier to understand the effects of utilization of EG. The bed properties are shown in Table 1. In the dehydration experiment, the apparatus (including piping, reaction chamber, and packed bed) was at first preheated at a temperature of $120^{\circ} \mathrm{C}$. The condensation temperature in the water reservoir was maintained at $20^{\circ} \mathrm{C}$ using a water chiller. In this manner, the dehydration pressure $P_{\mathrm{d}}$ was fixed at $2.3 \mathrm{kPa}$. During dehydration, the water reservoir was used for condensing the water vapor released from the reaction in the packed bed. Then, the reactor's heater was controlled to attain and maintain the inner wall temperature $\left(T_{\text {wall }}\right)$ at $400^{\circ} \mathrm{C}$ until a steady state of mass change of the reaction chamber and temperatures in the bed was reached. The kinetics of chemical reactions was analyzed from the mass change of the reaction chamber. The reactor's mass 
Table 1. Properties of the packed beds object of comparison.

\begin{tabular}{cccccc}
\hline Bed & $\begin{array}{c}\text { Mass of } \\
\mathrm{Mg}(\mathrm{OH})_{2} \\
{[\mathrm{~g}]}\end{array}$ & $\begin{array}{c}\text { Mass of } \\
\text { packed bed } \\
{[\mathrm{g}]}\end{array}$ & $\begin{array}{c}\text { Density of } \\
\text { particles } \\
{\left[\mathrm{g} \mathrm{cm}^{-3}\right]}\end{array}$ & $\begin{array}{c}\text { Density of bed, } \\
\rho_{\text {ini }} \\
{\left[\mathrm{g} \mathrm{cm}^{-3}\right]}\end{array}$ & $\begin{array}{c}\text { Thermal } \\
\text { conductivity, } \lambda_{\text {ini }} \\
{\left[\mathrm{W} \mathrm{m}^{-1} \mathrm{~K}^{-1}\right]}\end{array}$ \\
\hline $\begin{array}{c}\text { Pure-Mg(OH})_{2} \text { pellet } \\
\text { (random arranged) }\end{array}$ & 43.9 & 43.9 & 0.966 & 0.626 & 0.16 \\
$\begin{array}{c}\text { EM tablets } \\
\text { (piles arranged) }\end{array}$ & 43.6 & 49.1 & 1.056 & 0.714 & $\begin{array}{c}0.55 \text { radial } \\
0.45 \text { axial }\end{array}$ \\
\hline
\end{tabular}

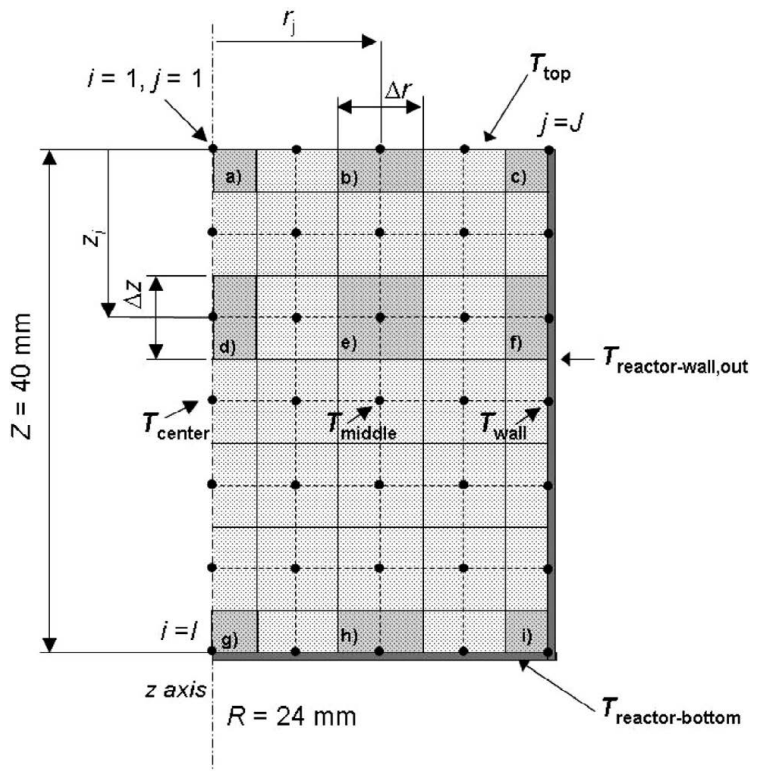

(a)

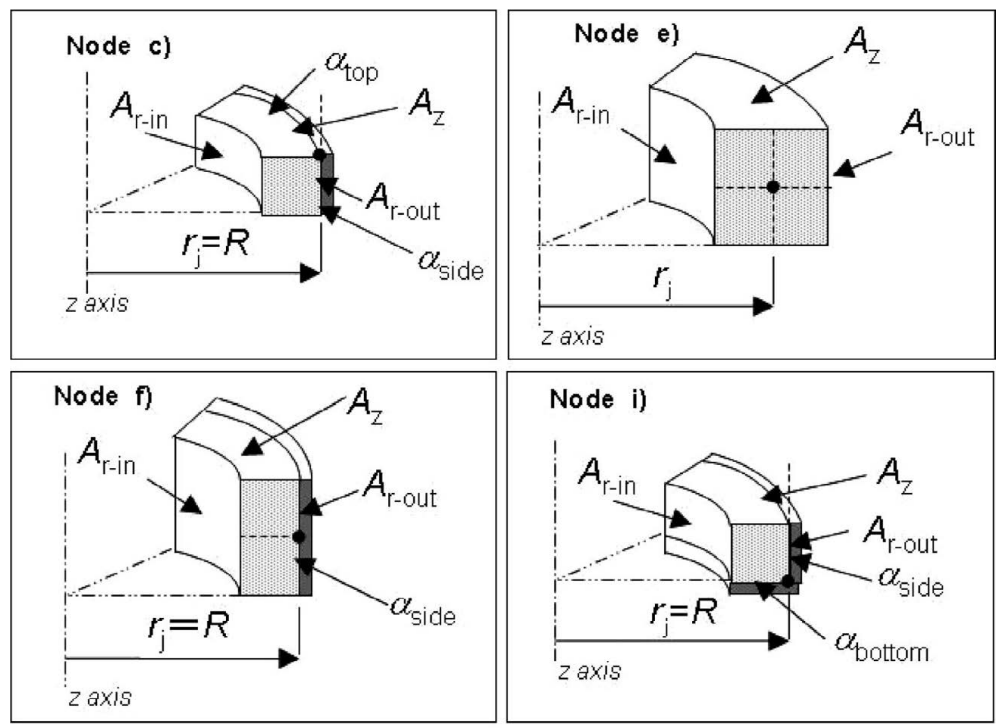

(b)

Fig. 3. Model of packed bed reactor used for the numerical analysis, (a) model at a cross section of packed bed reactor, (b) models of the representative nodes.

change, $\Delta m[\mathrm{~g}]$, was ascribed to the movement of water vapor between the packed bed reactor and the reservoir. The total reacted fraction, $x_{\text {tot }}[-]$, was calculated using Eq. (3):

$$
x_{\text {tot }}=\frac{\Delta m / M_{\mathrm{H}_{2} \mathrm{O}}}{m_{\mathrm{Mg}(\mathrm{OH})_{2}} / M_{\mathrm{Mg}(\mathrm{OH})_{2}}}
$$

where $m_{\mathrm{Mg}(\mathrm{OH})_{2}}[\mathrm{~g}]$ and $M\left[\mathrm{~g} \mathrm{~mol}^{-1}\right]$ are the initial amount of reactant charged in the bed and molecular weight of the substance, respectively. To demonstrate the heat transfer enhancement achieved with utilization of EG, thermal conductivities of both beds were measured by using an unsteady state hot wire method. Because EM tablets pile had anisotropic properties, its thermal conductivity was measured in the direction radial and axial to the direction of compression.

\section{Numerical Analysis Model of Packed Bed Reactor}

A numerical analysis of heat transfer in a packed bed reactor for heat storage process accompanied with endothermic $\mathrm{Mg}(\mathrm{OH})_{2}$ dehydration was discussed for understating of the importance of higher thermal conductivity in the reactor. Then, the results of the calculations were compared with the experimental ones.

\subsection{Definition of the Numerical Model}

Temporal changes of temperatures and reacted fraction in the packed bed reactor during the dehydration have been calculated by solving the energy balance equations. In particular, they consider the amount of heat stored by dehydration of $\mathrm{Mg}(\mathrm{OH})_{2}$ and the change of material's properties in function of the reaction's advancement. Figure 3 shows the two-dimensional cylindrical heat transfer domain representing a cross section of the experimental reactor bed. It has been divided into nodes using $\Delta r$ and $\Delta z$ as mesh sizes in the radial and axial direction, respectively. It is divided in a total number of $J$ columns and $I$ rows. With exclusion of the nodes on the axis $(j=1)$, which have a cylindrical shape, the general node at radius $\left(r_{\mathrm{j}}\right)$ of the bed has a annular shape with volume $V_{\mathrm{i}, \mathrm{j}}\left[\mathrm{m}^{3}\right]$, while $A_{\mathrm{r}-\mathrm{in}}\left[\mathrm{m}^{2}\right]$ and $A_{\mathrm{r}-\text { out }}\left[\mathrm{m}^{2}\right]$ are the side areas and $A_{\mathrm{z}}\left[\mathrm{m}^{2}\right]$ is the area of the top and bottom bases of the node. Every node is characterized by a local value of density, $\rho_{\mathrm{i}, \mathrm{j}}\left[\mathrm{kg} \mathrm{m}^{-3}\right]$, specific heat capacity $c_{\mathrm{i}, \mathrm{j}}\left[\mathrm{J} \mathrm{kg}^{-1} \mathrm{~K}^{-1}\right]$, and effective thermal conductivities $\lambda_{\mathrm{r}}$ and $\lambda_{\mathrm{z}}\left[\mathrm{W} \mathrm{m}^{-1} \mathrm{~K}^{-1}\right]$, respectively in the radial and axial directions. Those properties are function of the local reacted fraction, $x_{\mathrm{i}, \mathrm{j}}[-]$ and local temperature, $T_{\mathrm{i}, \mathrm{j}}\left[{ }^{\circ} \mathrm{C}\right]$.

For every node, the governing heat transfer equation is expressed as:

$$
\rho c \frac{\partial T}{\partial \tau}=\lambda \cdot \nabla^{2} T+s
$$

Equation (2) allows calculating the temperature field in the packed bed where heat is exchanged by conduction (anisotropic thermal conductivity is expressed by the tensor $\lambda$ ) and heat is stored chemically with a heat storage rate $s$. 
[ $\left.\mathrm{J} \mathrm{s}^{-1} \mathrm{~m}^{-3}\right]$. For each node on Fig. 3, Eq. (4) were discretized in the radial and axial direction and expressed accordingly to the finite difference scheme. ${ }^{11)}$ Implicit method was utilized, therefore the equation for temperature $T_{\mathrm{i}, \mathrm{j}}$ at time $\tau+$ $\Delta \tau[\mathrm{s}]$ of the generic node is given by:

$$
\begin{aligned}
& \frac{\lambda_{r i, j} A_{r-\text { out } i, j}}{\Delta r} \cdot\left(T_{i, j+1}-T_{i, j}\right)+\frac{\lambda_{r i, j} A_{r-i n i, j}}{\Delta r} \cdot\left(T_{i, j-1}-T_{i, j}\right) \\
& +\frac{\lambda_{z i, j} A_{z i, j}}{\Delta z} \cdot\left(T_{i-1, j}-T_{i, j}\right)+\frac{\lambda_{z i, j} A_{z i, j}}{\Delta z} \cdot\left(T_{i+1, j}-T_{i, j}\right) \\
& +\sum E_{\mathrm{bound}}=s_{i, j} \cdot V_{i, j}+\frac{\rho_{i, j} \cdot c_{i, j}}{\Delta \tau} \cdot V_{i, j} \cdot\left(T_{i, j}-T_{i, j}^{\circ}\right)
\end{aligned}
$$

where $\Delta \tau[\mathrm{s}]$ is the time step of the calculations, $T^{\circ}{ }_{\mathrm{i}, \mathrm{j}}$ is the temperature at time $\tau[\mathrm{s}], s_{\mathrm{i}, \mathrm{j}}$ is the local heat storage rate per unit volume $\left[\mathrm{J} \mathrm{s}^{-1} \mathrm{~m}^{-3}\right]$, which corresponds to the heat consumed by the endothermic dehydration in the time $\Delta \tau$, while $\Sigma E_{\text {bound }}$ [W] is the term for taking into account the boundary conditions. $\Delta \tau$ of $10 \mathrm{~s}$ was used for the calculations. The terms $E_{\text {bound, }} s_{\mathrm{i}, \mathrm{j}}$ and the properties of materials $\rho_{\mathrm{i}, \mathrm{j}}$ (density) and $c_{i, j}$ (specific heat capacity) were evaluated separately. In particular, the values of $\rho_{\mathrm{i}, \mathrm{j}}$ and $c_{\mathrm{i}, \mathrm{j}}$ are considered constant within the time step $\Delta \tau$, but their value is recalculated in function of the new temperature calculated for time $\tau+\Delta \tau$.

\subsection{Boundary Conditions}

For a generic node of the packed bed (node e), as shown on Fig. 3, Eq. (2) can be used straightforward, with $\Sigma E_{\text {bound }}=$ 0 . On the boundaries of the reactor (for instance side and corner, respectively node f) and i) in Fig. 3), the Eq. (2) has to include the boundary conditions. The numerical model includes also the reactor's wall, having a thickness of $2 \mathrm{~mm}$.

On the vertical outer side surface of the reactor, heat is supplied by the sheath heater. Its temperature $T_{\text {reactor-wall,out }}$ was measured from the bed experiment. For the nodes in contact with the wall (node f), $j=J$, in Fig. 3(b)), Eq. (2) is modified as follows:

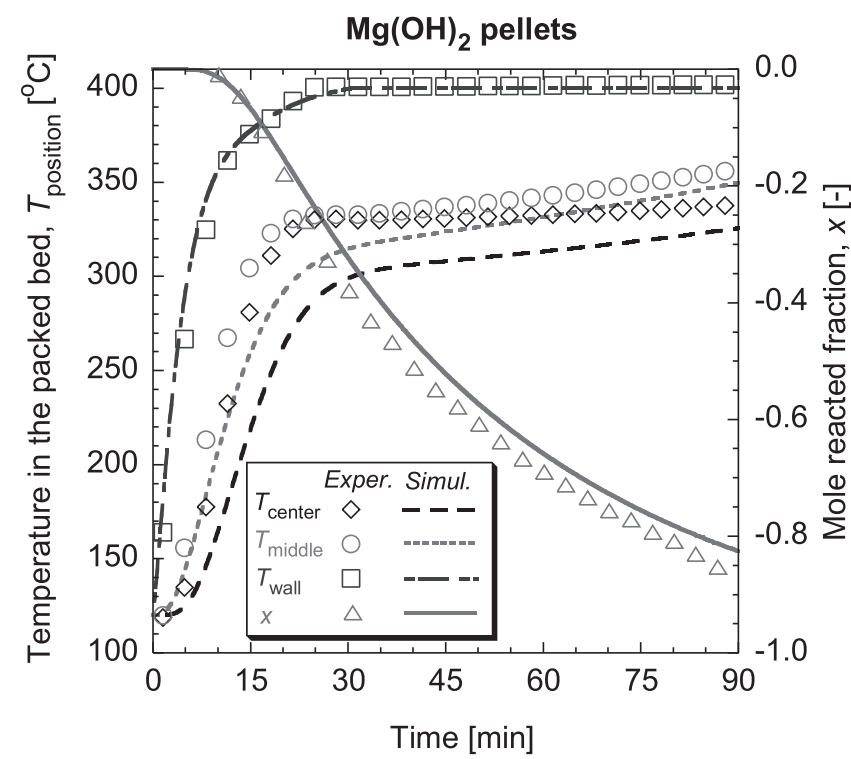

(a)

$$
\begin{aligned}
& \frac{\lambda_{z i, J} A_{z i, J}}{\Delta z} \cdot\left(T_{i-1, J}-T_{i, J}\right)+\frac{\lambda_{z i, j} A_{z i, J}}{\Delta z} \cdot\left(T_{i+1, J}-T_{i, J}\right) \\
& +\frac{\lambda_{r i, J} A_{r-i n i, J}}{\Delta r} \cdot\left(T_{i, J-1}-T_{i, J}\right)+E_{\text {side }} \\
& =s_{i, J} \cdot V_{i, J}+\frac{\rho_{i, J} \cdot c_{i, J}}{\Delta \tau} \cdot V_{i, J} \cdot\left(T_{i, J}-T_{i, J}^{\circ}\right)
\end{aligned}
$$

where,

$$
E_{\text {side }}=\alpha_{\text {side }} \cdot A_{\text {r-out } i, J} \cdot\left(T_{i, J}-T_{\text {reactor-wall, in }}\right)
$$

The coefficient $\alpha_{\text {side }}\left[\mathrm{W} \mathrm{m}{ }^{-2} \mathrm{~K}^{-1}\right.$ ] represents the thermal conductance between reactor's wall and packed bed materials. Similarly, for the corner on the bottom side of the reactor (node $i$ ) in Fig. 3(b),

$$
\begin{aligned}
& \frac{\lambda_{r I, J} A_{r-i n I, J}}{\Delta r} \cdot\left(T_{I, J-1}-T_{I, J}\right)+\frac{\lambda_{z I, J} A_{z I, J}}{\Delta z} \cdot\left(T_{I-1, J}-T_{I, J}\right) \\
& +E_{\text {bottom }}+E_{\text {side }}=s_{I, J} \cdot V_{I, J}+\frac{\rho_{I, J} \cdot c_{I, J}}{\Delta \tau} \cdot V_{I, J} \cdot\left(T_{I, J}-T_{I, J}^{\circ}\right) \ldots
\end{aligned}
$$

where,

$$
E_{\text {bottom }}=\alpha_{\text {bottom }} \cdot A_{\mathrm{z} I, J} \cdot\left(T_{I, J}-T_{\text {reactor-bottom }}\right)
$$

and

$$
E_{\text {side }}=\alpha_{\text {side }} \cdot A_{\mathrm{r}-\text { out } I, J} \cdot\left(T_{I, J}-T_{\text {reactor-wall, in }}\right)
$$

On the reactor's bottom, there was not any heater for controlling temperature because lack of physical space for setting it; heat was dissipated through the stems beneath the reactor and then to the vacuum chamber. It was observed experimentally that the value of $T_{\text {reactor-bottom was lower than }}$ $T_{\text {reactor-wall, out }}$ and followed the relation expressed on Eq. (11).

$$
T_{\text {reactor-bottom }}=0.785 T_{\text {reactor-wall,out }}
$$

This relation was satisfied also when loading other materials in the reactor, so it was assumed that Eq. (11) expresses

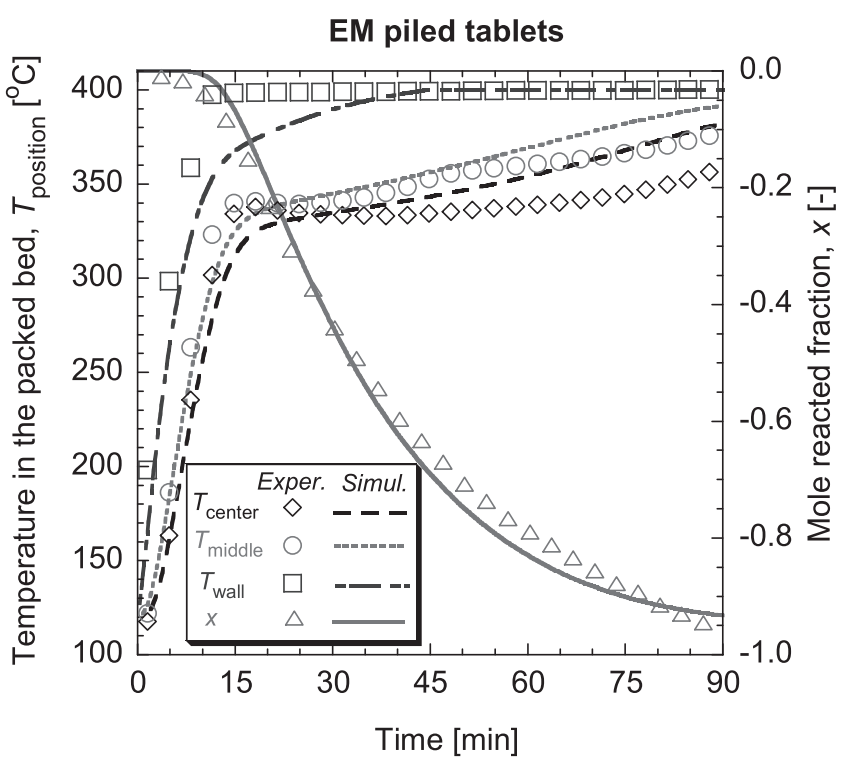

(b)

Fig. 4. Comparison between experimental data and numerical analysis for $\operatorname{Mg}(\mathrm{OH})_{2}$ dehydration of heat storage operation. a) comparison between simulations and experimental results in a packed bed of $\mathrm{Mg}(\mathrm{OH})_{2}$ pellets $\left(T_{\text {reactor-wall,in }}=\right.$ $\left.400^{\circ} \mathrm{C}, P_{\text {cond }}=2.3 \mathrm{kPa}\right)$. b) comparison between simulations and experimental results in a packed bed of EM piled tablets $\left(T_{\text {reactor-wall,in }}=400^{\circ} \mathrm{C}, P_{\text {cond }}=2.3 \mathrm{kPa}\right)$. 
Table 2. Heat transfer coefficients used at the boundaries.

\begin{tabular}{lccc}
\hline \multicolumn{1}{c}{ Material in the bed } & $\begin{array}{c}\alpha_{\text {side }} \\
{\left[\mathrm{W} \mathrm{m}^{-2} \mathrm{~K}^{-1}\right]}\end{array}$ & $\begin{array}{c}\alpha_{\text {bottom }} \\
{\left[\mathrm{W} \mathrm{m}^{-2} \mathrm{~K}^{-1}\right]}\end{array}$ & $\begin{array}{c}\alpha_{\text {top }} \\
{\left[\mathrm{W} \mathrm{m}^{-2} \mathrm{~K}^{-1}\right]}\end{array}$ \\
\hline $\mathrm{Mg}(\mathrm{OH})_{2}$ pellets randomly arranged & 60 & 60 & 1 \\
EM tablets arranged in piles & 60 & 60 & 5 \\
\hline
\end{tabular}

a constant property of the experimental apparatus.

For the nodes a), b) and c) (corresponding to the row index $i=1$ ), the equations were written similarly to Eqs. (3) and (5), and the boundary condition corresponding to the heat loss from the top of the reactor was given by:

$$
E_{\text {top }}=\alpha_{\text {top }} \cdot A_{\mathrm{z} 1, j} \cdot\left(T_{1, j}-T_{\text {top }}\right)
$$

where $T_{\text {top }}$ is the temperature of the chamber $\left(120^{\circ} \mathrm{C}\right)$ which is constant during the experiments and the coefficient $\alpha_{\text {top }}$ represents a global heat transfer coefficient. The values of $\alpha_{\text {top }}, \alpha_{\text {bottom }}$ and $\alpha_{\text {side }}\left[\mathrm{W} \mathrm{m}^{-2} \mathrm{~K}^{-1}\right.$ ] were assumed as constants from a preliminary numerical analysis. Their values are given on Table 2. The analysis indicated that on the top of the reactor, the value of $\alpha_{\text {top }}$ for EM might be different from the one of $\mathrm{Mg}(\mathrm{OH})_{2}$. It is likely due to the different emissivity of materials.

Finally, the side of the steel wall of the reactor was considered. The properties of stainless steel were assumed as $\lambda_{\text {steel }}=25 \mathrm{Wm}^{-1} \mathrm{~K}^{-1}$, density $\rho_{\text {steel }}=7500 \mathrm{~kg} \mathrm{~m}^{-3}$ and specific heat capacity $c_{\text {steel }}=500 \mathrm{~J} \mathrm{~g}^{-1} \mathrm{~K}^{-1}$. As the thickness of the steel wall is small compared to the packed bed radius, it was necessary to divide the domain with a smaller $\Delta r_{\text {steel }}$ while, it was kept $\Delta z=\Delta z_{\text {steel. }}$. This mesh was prepared only for the side surface of the reactor, where heat is supplied and the temperature on the reactor's outer side was controlled by instrumentation, necessary for reaching and maintaining a certain constant temperature value. However, on the reactor's bottom, there was not any heater for the purpose; heat was dissipated through the stems beneath the reactor and then to the vacuum chamber. As the bottom surface is relatively smaller than the side one and because of the complicated modeling, which requires further general assumptions, it was preferred to utilize directly Eq. (11) obtained through experimental work on several packed beds.

\subsection{Reaction Rates and Heat Storage Term}

In previous studies, ${ }^{12-14)}$ it was shown that $\mathrm{Mg}(\mathrm{OH})_{2}$ dehydration is a first order reaction. The rate equation is expressed as follows:

$$
-\frac{d x}{d \tau}=k x
$$

where $k\left[\mathrm{~s}^{-1}\right]$ is the reaction rate constant. By integration of Eq. (13), it is obtained:

$$
\ln x_{i, j}=k_{i, j} \cdot \tau+\ln x_{0}
$$

The values of $k$ were determined experimentally with a previous study ${ }^{15)}$ for a kinetic analysis of dehydration in a thermo-gravimetric apparatus (ULVAC TG-9600, Japan) in function of different dehydration temperature conditions $\left(300,340,370\right.$ and $\left.400^{\circ} \mathrm{C}\right)$. The reaction rate constant and the values of activation energy $E_{\mathrm{a}}\left[\mathrm{J} \mathrm{mol}^{-1}\right]$ could be expressed by the following Arrhenius equation:

$$
k=A_{0} \cdot e^{-E_{\mathrm{a}} / R_{\mathrm{g}} T}
$$

where $A_{0}\left[\mathrm{~s}^{-1}\right], R_{\mathrm{g}}\left(=8.314 \mathrm{~J} \mathrm{~mol}^{-1} \mathrm{~K}^{-1}\right)$, and $T[\mathrm{~K}]$ are frequency factor, universal constant of gas, and absolute temperature, respectively. In particular, in the numerical model, the reaction will proceed with a reaction rate constant $k_{\mathrm{i}, \mathrm{j}}$ function of the temperature $T_{\mathrm{i}, \mathrm{j}}$ of the node. Equation (15) can then be expressed in the form

$$
k_{i, j}=A_{0} \cdot e^{-E_{\mathrm{a}} / R_{\mathrm{g}} T_{i, j}}
$$

In order to calculate the reacted fraction $x_{\mathrm{i}, \mathrm{j}}$ of the generic node can be calculated from Eq. (14), it was considered that $k_{\mathrm{i}, \mathrm{j}}$ did not change during the interval of calculations, $\Delta \tau$, but its value was recalculated at the new calculation time $\tau+\Delta \tau$ in function of the temperature of the node. Therefore, at time $\tau+\Delta \tau$ the Eq. (14) can be rewritten as:

$$
\ln x_{i, j}^{\prime}=k_{i, j} \cdot(\tau+\Delta \tau)+\ln x_{0}
$$

where $x^{\prime}{ }_{i, j}$ is the reacted fraction at time $\tau+\Delta \tau$. Therefore $x^{\prime}{ }_{i, j}$ can be expressed as

$$
x_{i, j}^{\prime}=x_{i, j} \cdot e^{k_{i, j} \cdot \Delta \tau}
$$

The local heat storage rate per unit volume $s_{\mathrm{i}, \mathrm{j}}$ during the time step of calculations $\Delta \tau$ is given by:

$$
s_{i, j}=\frac{-\Delta H^{\circ}}{\Delta \tau} \cdot \rho_{i n i} \cdot \Delta x_{i, j}
$$

where

$$
\Delta x_{i, j}=x_{i, j}^{\prime}-x_{i, j}
$$

In case of packed bed of EM, the mixing ratio $\psi[-]$, defined previously as the ratio between the mass of $\mathrm{Mg}(\mathrm{OH})_{2}$ and the mass of EG used in the preparation of EM, has to be also accounted:

$$
s_{i, j}=\frac{-\Delta H^{\circ}}{\Delta \tau} \cdot \rho_{i n i} \cdot \Delta x_{i, j} \cdot \frac{\psi}{\psi+1}
$$

\subsection{Thermal Properties of Materials}

For what concerns the thermal properties of materials in the packed beds, their thermal conductivity was measured before and after dehydration ( $\lambda_{\text {ini }}$ and $\lambda_{\text {end }}$, respectively) in a previous study. ${ }^{14)}$ It was assumed that thermal conductivity changed linearly with mole reacted fraction, as expressed in the following equation.

$$
\lambda_{i, j}=\left(1-x_{i, j}\right) \cdot \lambda_{\text {ini }}+x_{i, j} \cdot \lambda_{\text {end }}
$$

The value of, $\lambda_{\text {end }}$ corresponding to the thermal conductivity of materials in the dehydrated state, was measured after a separate dehydration of materials in a muffle furnace replicating the temperature of dehydration in the packed bed experiments. It was observed that the $\lambda_{\text {end }}$ of packed beds of $\mathrm{Mg}(\mathrm{OH})_{2}$ pellets or slabs of EM reported a thermal conductivity that was half of the initial $\lambda_{\text {ini. }}$.

Specific heat capacities of $\mathrm{Mg}(\mathrm{OH})_{2}, \mathrm{MgO}$ and EG were measured with DSC. It was calculated for every node at every time step in function of temperature and reacted fraction by using the following equation:

$$
c_{i, j}=\left(1-x_{i, j}\right) \cdot c_{\mathrm{Mg}(\mathrm{OH})_{2}}\left(T_{i, j}\right)+x_{i, j} \cdot c_{\mathrm{MgO}}\left(T_{i, j}\right)
$$

To take into account of the heat capacity of expanded 
graphite, Eq. (17) is modified as follows:

$$
\begin{aligned}
& c_{i, j}=\left[\left(1-x_{i, j}\right) \cdot c_{\mathrm{Mg}(\mathrm{OH})_{2}}\left(T_{i, j}\right)+x_{i, j} \cdot c_{\mathrm{MgO}}\left(T_{i, j}\right)\right] \\
& \frac{\psi}{\psi+1}+c_{\mathrm{EG}}\left(T_{i, j}\right) \cdot \frac{1}{\psi+1}
\end{aligned}
$$

For what concerns density, it was calculated as the ratio between the mass of the node and the volume of the node.

$$
\rho_{i, j}=\frac{\left(1-x_{i, j}\right) \cdot m_{\mathrm{Mg}(\mathrm{OH})_{i}, j}+x_{i, j} \cdot m_{\mathrm{MgO} i, j}}{V_{i, j}}
$$

or

$$
\rho_{i, j}=\frac{\left(1-x_{i, j}\right) \cdot m_{\mathrm{Mg}\left(\mathrm{OH}_{2} i, j\right.}+x_{i, j} \cdot m_{\mathrm{MgO} i, j}+m_{\mathrm{EG} i, j}}{V_{i, j}}
$$

in the case of packed beds of EM tablets. These properties were updated at every time step in function of the new values of temperature $T_{\mathrm{i}, \mathrm{j}}$ and mole reacted fraction $x_{\mathrm{i}, \mathrm{j}}$.

\section{Results of Experiments and Numerical Analysis for the Packed Bed}

Finite difference implicit method was used and the algebraic system of equations was solved at every time step using the Gauss-Seidel iteration method. Figure 4 shows the comparison between experimental data and simulation of dehydrations in a packed bed of $\mathrm{Mg}(\mathrm{OH})_{2}$ pellet and EM tablet bed, respectively.

The temperatures across the radius at height $Z / 2$ have been considered. As shown in Fig. $3, T_{\text {center, }} T_{\text {middle, }}$, and $T_{\text {wall }}$ are, respectively, the temperature at the center of the bed, at the position $\mathrm{R} / 2$ and at the position in contact with the wall of the reactor. The results showed a substantial agreement between experimental results and calculated data. Some discrepancies were observed especially between the measured and calculated temperatures. The reason of this difference is related to the effect of pellet/tablet arrangement, proper contact between thermocouples and materials in the bed and accuracy of position of the thermocouples. In the simulations, the calculated temperatures represent the node temperature: every node of the packed bed, having an annular shape, is considered to have homogeneous temperature. Every node is also characterized by a value of thermal conductivity given by measurements of apparent thermal conductivity (Table 1). Such value of apparent thermal conductivity was used for taking into account the effects of non homogeneity of the bed. On the other hand, it was observed that the calculations of total reacted fraction $x_{\text {tot }}$, which is representative of all the local reacted fractions, could fit well the experimental results. It is therefore possible to discuss the results of mole reacted fraction without considering the discrepancy between node temperature and point measured temperature. The numerical model allows calculating the local concentrations of $\mathrm{Mg}(\mathrm{OH})_{2}$, $\xi_{\text {position }}[\%]$, for a certain position of the packed bed. Figure 5 shows the values of $\xi_{\text {position }}$ for three positions of the packed bed, respectively, on the wall, $\xi_{\text {wall, }}$ on the middle position of $R / 2, \xi_{\text {middle }}$ and at the center of the bed, $\xi_{\text {center. }}$.

On the position close to the wall, $\xi_{\text {wall }}$ calculated for the bed of $\mathrm{Mg}(\mathrm{OH})_{2}$ decreased earlier than in case of bed of EM tablets. On the other hand, for the middle and center positions, it was clear that the reaction was advanced much fast-

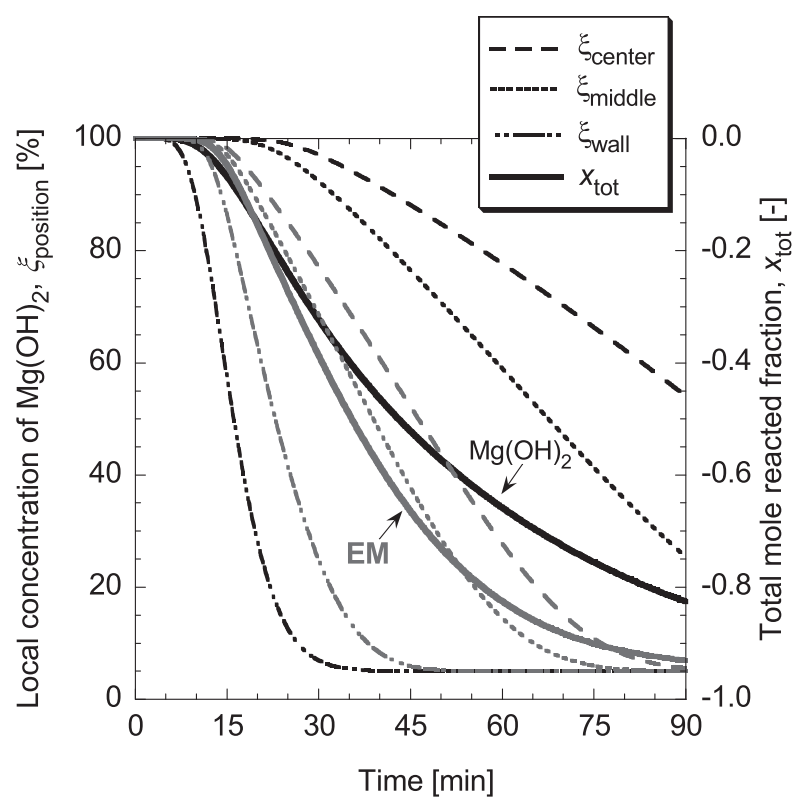

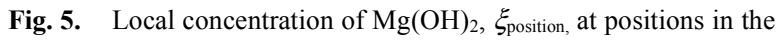
bed.

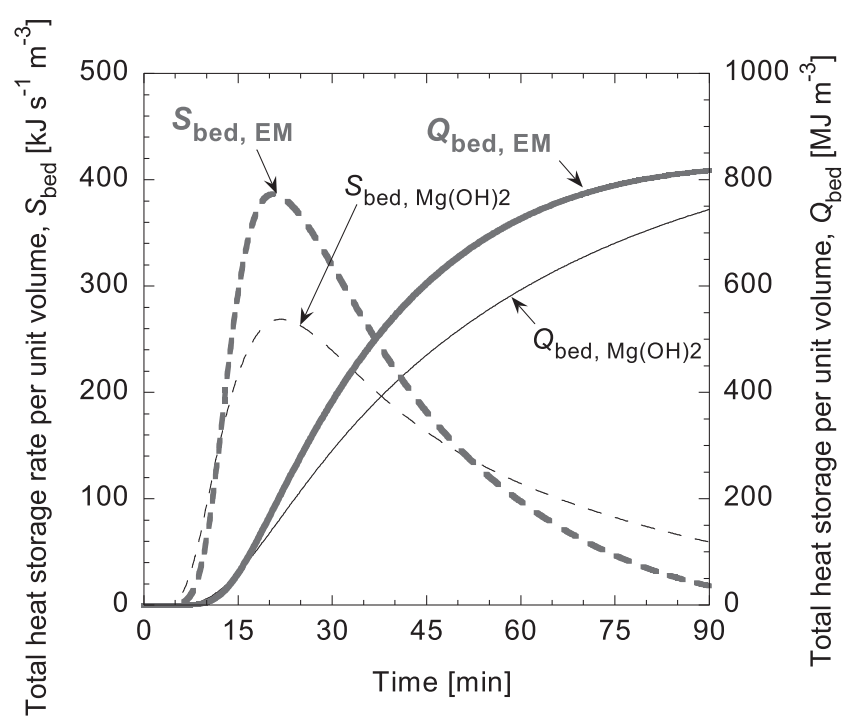

Fig. 6. Comparison of total heat storage $Q_{\text {bed }}$ and total heat storage rate $S_{\text {bed }}$

er in EM bed. Moreover, the reaction in $\mathrm{Mg}(\mathrm{OH})_{2}$ pellet bed could not be completed in 90 minutes. This demonstrates that thermal conductivity enhancement provided by EG is the key point for improving heat diffusion in the regions far from the heat source. The temperature in the bed of EM was increased more uniformly, therefore dehydration could start earlier in the whole bed, as higher temperature allowed increasing the rate of reaction. It is expected that by improving the contact condition between EM bed and reactor's heated surface, the performance would be further improved.

Figure 6 shows the total heat storage per unit volume $Q_{\text {bed }}$ $\left[\mathrm{MJ} \mathrm{m}^{-3}\right]$ :

$$
Q_{\text {bed }}=\frac{-\Delta H^{\circ}}{M_{\mathrm{Mg}(\mathrm{OH})_{2}}} \cdot \rho_{\mathrm{ini}} \cdot \Delta x \cdot \frac{\psi}{\psi+1}
$$

and the total heat storage rate per unit volume $S\left[\mathrm{~kJ} \mathrm{~s}^{-1} \mathrm{~m}^{-3}\right]$, calculated with: 


$$
S_{\text {bed }}=\frac{\sum_{i=1, j=1}^{i=I, j=J} s_{i, j} \cdot V_{i, j}}{\pi \cdot R^{2} \cdot Z}
$$

The results shows that EM tablet bed had larger heat storage rate than $\operatorname{Mg}(\mathrm{OH})_{2}$ pellets, in other words, the same amount of heat can be stored more promptly within the same volume in a shorter time. It is concluded that EM tablets would be a more suitable material for practical packed bed application than $\mathrm{Mg}(\mathrm{OH})_{2}$ pellets.

\section{Numerical Analysis of Chemical Heat Storage Units (CHSU)}

In this section, the numerical model has been utilized for a provisional analysis of a waste heat recovery system. In particular, Chemical Heat Storage Units (CHSU) have been proposed and analyzed numerically. They would be utilized for waste heat recovery from steel making process, by harvesting heat released by the hot slabs produced continuously. A single CHSU unit consists in a cylindrical steel pipe, with an assumed length of $2 \mathrm{~m}$, filled with a packed bed of a CHS material, for example $\mathrm{Mg}(\mathrm{OH})_{2}$ pellets or piles of EM tablets. A bundle of CHSU would be arranged over the cooling slab as depicted on Fig. 7 with a certain pitch, $p[\mathrm{~m}]$.

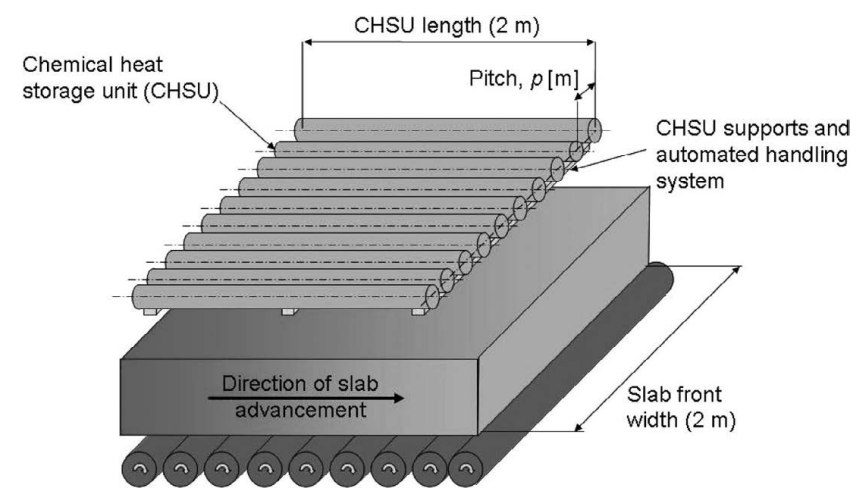

Fig. 7. Scheme of waste heat recovery system using Chemical Heat Storage Units.
It was assumed that they collected waste heat at $400^{\circ} \mathrm{C}$ which came out from the slab moving beneath, as represented on Fig. 8. Waste heat transferred by radiation and convection to the CHSU, is stored by $\mathrm{Mg}(\mathrm{OH})_{2}$ dehydration contained in the CHSU. When dehydration in CHSU is terminated, CHSU would be replaced with fresh ones through some automation. The hot CHSU would be transported into another place of the steel making plant for reutilization of heat by operating the hydration reaction. In this analysis, attention will be focused on the heat storage process.

An analysis for observation of the heat storage performance of CHSU in function of the pipe diameter was discussed numerically. The thickness of pipe was set at $2 \mathrm{~mm}$ whichever the diameter. The numerical analysis aimed to obtain information about the amounts of heat stored as sensible heat (into the steel or in the packed bed) and chemical heat. The ultimate goal was to find the optimal diameter of the CHSU for heat recovery process depicted in Fig. 7.

The previous numerical model showed in Section 3 was used for the purpose after modifying some boundary conditions and assumptions, as described in the following list:

- Densities of packed beds in the CHSU were considered the same as in the packed bed reactor experiments $\left(0.626 \mathrm{~g} \mathrm{~cm}^{-3}\right.$ for $\mathrm{Mg}(\mathrm{OH})_{2}$ pellets and $0.714 \mathrm{~g} \mathrm{~cm}^{-3}$ for EM);

- Initial temperature of packed bed was assumed $150^{\circ} \mathrm{C}$;

- On the external surface of the CHSU, heat transfer occurs by convection and radiation with a global heat transfer coefficient was assumed, $\alpha_{\text {out }}=150 \mathrm{~W} \mathrm{~m}^{-2} \mathrm{~K}^{-1}$;

- It is assumed that temperature around the CHSU is constant at $400^{\circ} \mathrm{C}$. This condition might be achieved by keeping CHSU rotating along their longitudinal axis and/or reflecting back heat through a curved mirror.

- The values of thermal conductivity, specific heat capacity and reaction rate constants of heat storage materials, which were measured directly or determined experimentally, were the same as in the previous analysis on the experimental packed bed reactor,

- The internal coefficients of contact resistance to heat transfer $\alpha_{\text {side }}$ was kept the same as in the previous numerical analysis. It was considered that the both ends

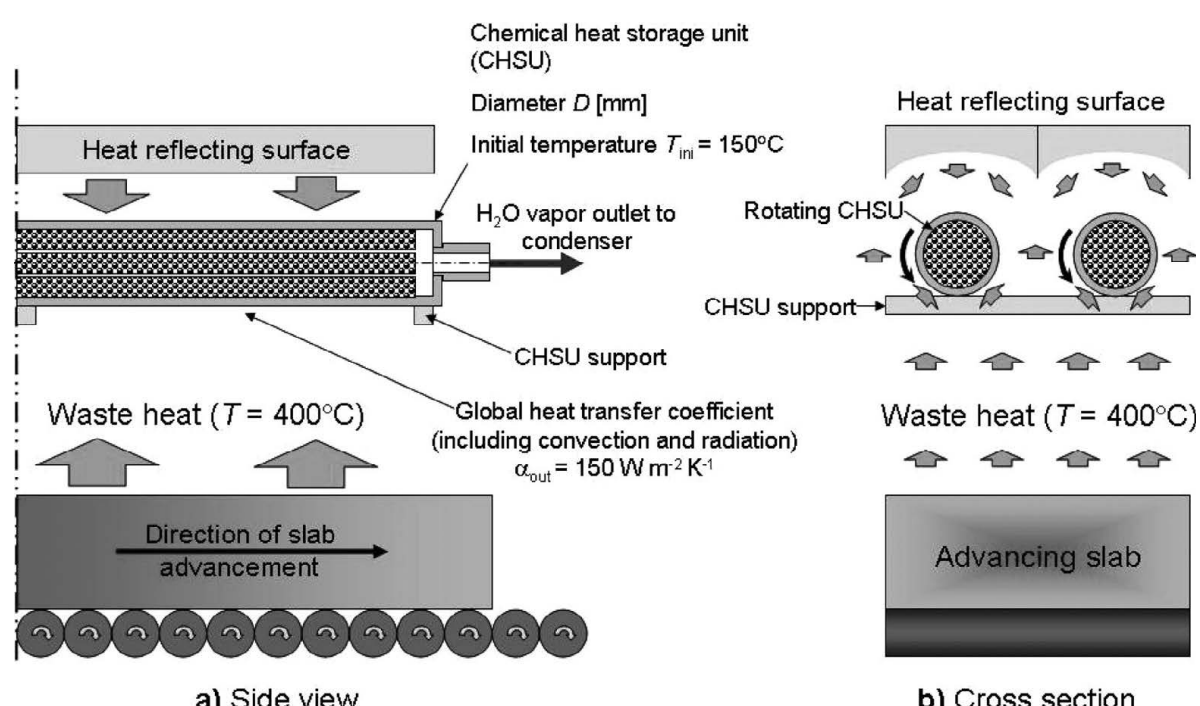

Fig. 8. Outer boundary conditions utilized for the numerical analysis of CHSU system, a) side view, b) cross section. 
of the single CHSU were adiabatic surfaces, then it was assumed that $\alpha_{\text {bottom }}=\alpha_{\text {top }}=0$.

- The outer diameters

- $D$ of the CHSU were $40,52,64,76,88$ and $100 \mathrm{~mm}$, respectively.

Figure 9 shows the amounts of heat stored after $60 \mathrm{~min}$ of dehydration for a single CHSU charged two packed bed materials in function of CHSU diameter. The columns are divided in 3 sections, which represent the heat storage ratios between heat stored as sensible heat (into the steel, $\Theta_{\mathrm{s}, \text { steel }}$ $[\mathrm{MJ}]$ and into the packed bed $\left.\Theta_{\mathrm{s}, \text { bed }}[\mathrm{MJ}]\right)$ and chemically stored heat, $\Theta_{\text {ch,bed }}$ with respect of the total heat stored $\Theta_{\text {tot,unit }}$ defined as:

$$
\Theta_{\text {tot,unit }}=\Theta_{\text {s,steel }}+\Theta_{\text {s,bed }}+\Theta_{\text {ch,chem }}
$$

Hence, the three heat storage ratios $\Omega_{\mathrm{s} \text {, steel }}, \Omega_{\mathrm{s} \text {, bed }}, \Omega_{\mathrm{ch} \text {, bed, }}$ are defined, respectively, as:

$$
\begin{aligned}
& \Omega_{\text {s, steel }}=\frac{\Theta_{\text {s,steel }}}{\Theta_{\text {tot,unit }}}[\%] \\
& \Omega_{\text {s, bed }}=\frac{\Theta_{\text {s,bed }}}{\Theta_{\text {tot,unit }}}[\%] \\
& \Omega_{\text {ch, bed }}=\frac{\Theta_{\text {ch,bed }}}{\Theta_{\text {tot,unit }}}[\%]
\end{aligned}
$$

The plot shows that for larger diameters of the CHS unit, the ratio of chemical heat storage $\Omega_{\mathrm{ch} \text {, bed }}$, decreased, especially at over $76 \mathrm{~mm}$ for $\mathrm{Mg}(\mathrm{OH})_{2}$ pellets or $100 \mathrm{~mm}$ for EM tablets. For these diameters in fact, more than $50 \%$ of heat would be stored as sensible heat because dehydrations in the larger cross sections are not advanced enough in the same operation time by limitation of heat conduction. Moreover, for larger diameters, the chemical heat storage performance results poor because of the larger heat capacity of the $\mathrm{CHSU}$, as most of heat is used to raise the bed's temperature rather than being stored by dehydration. However, by extending the time for dehydration to more than $60 \mathrm{~min}$, it would be possible to store more heat also in the CHSU having a larger diameter. The plots indicate that under the same conditions of imposed temperature on the outer wall of the CHSU, EM tablets could store more heat per unit time compared to $\mathrm{Mg}(\mathrm{OH})_{2}$ pellets.

Then, the total heat storage of a system made of CHSU bundles $\Theta_{\text {tot, bundle }}[\mathrm{MJ}]$ arranged as in Fig. 7, is plotted on Fig. 10. Considering a pitch between the CHSU $p=1.2 \mathrm{D}[\mathrm{m}]$ and a front length of $2 \mathrm{~m}$, the number of CHSU that can be positioned is shown on Table 3.

Despite the lesser amount of CHSU that can be displaced, the value of $\Theta_{\text {tot, bundle }}$ increases for larger outer diameter of

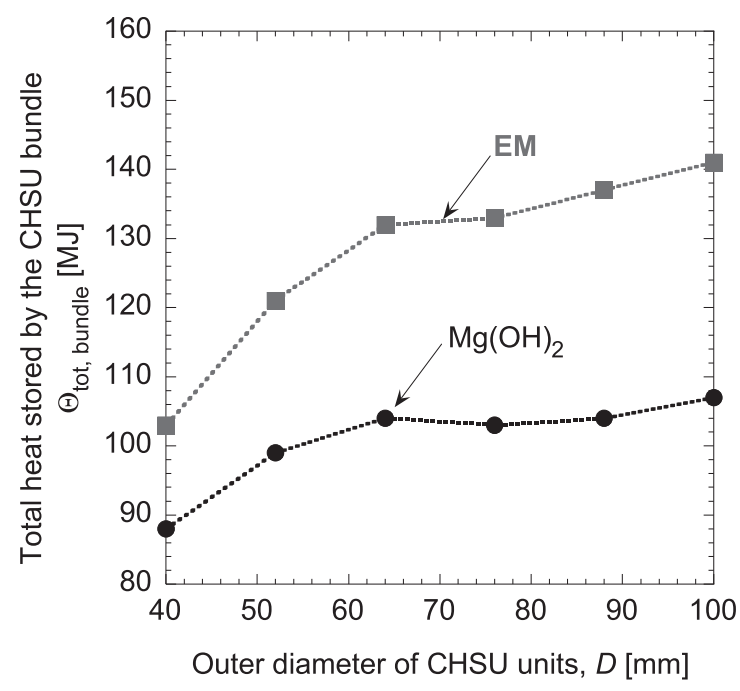

Fig. 10. Total heat stored $\Theta_{\text {tot, bundle }}[\mathrm{MJ}]$ by the CHSU bundles in function of their outside diameter, $D[\mathrm{~mm}]$. Results refer to $60 \mathrm{~min}$ of simulation, with $T_{\mathrm{ini}}=150^{\circ} \mathrm{C}$ and heat temperature of $400^{\circ} \mathrm{C}$.

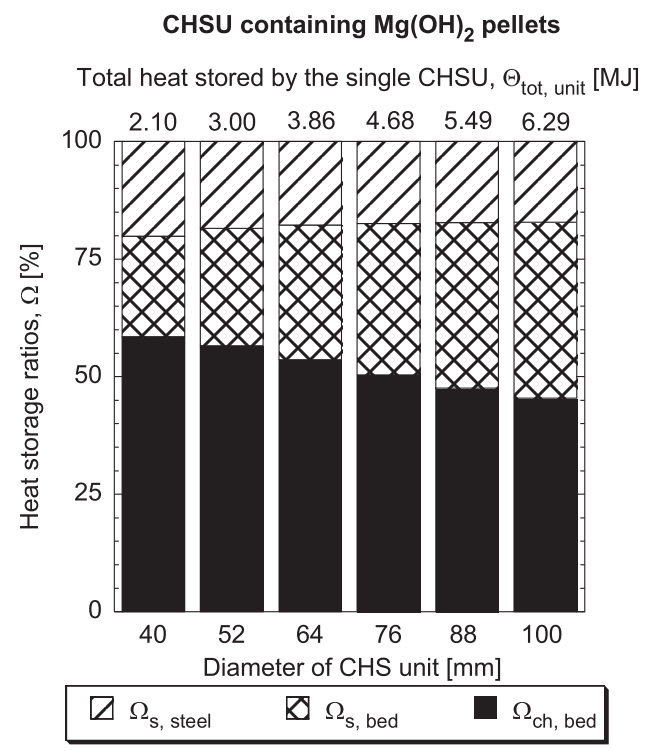

(a)

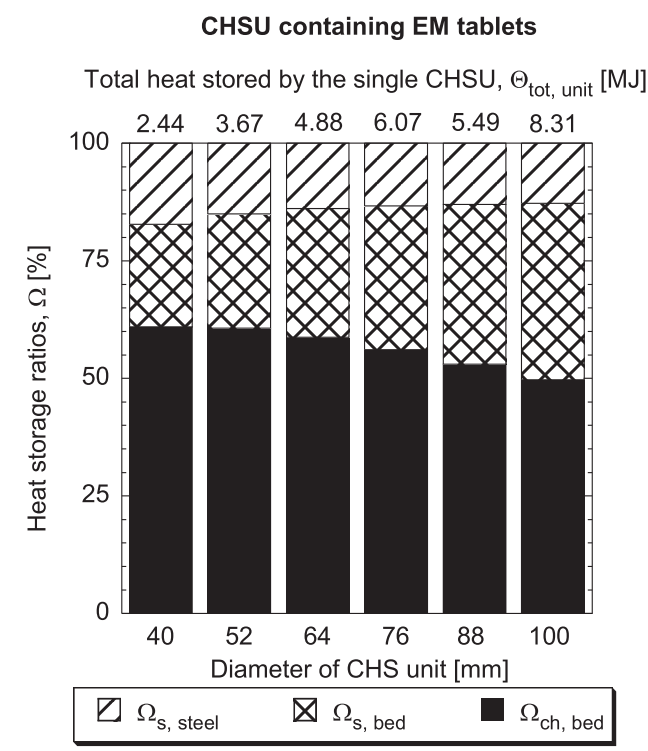

(b)

Fig. 9. Heat storage ratios $\Omega$ (sensible on steel, sensible on bed, chemical on bed) for a single CHSU in function of their diameter and packed bed material, calculated with respect of the total heat stored by a single CHSU, $\Theta_{\text {tot,unit }}[\mathrm{MJ}]$. a) Heat storage ratios $\Omega$ in a single CHSU filled with $\mathrm{Mg}(\mathrm{OH})_{2}$ pellets $\left(T_{\text {out }}=400^{\circ} \mathrm{C}, T_{\text {ini }}=150^{\circ} \mathrm{C}\right.$, simulation time $=$ $60 \mathrm{~min})$. b) Heat storage ratios $\Omega$ in a single CHSU filled with EM tablets $\left(T_{\text {out }}=400^{\circ} \mathrm{C}, T_{\text {ini }}=150^{\circ} \mathrm{C}\right.$, simulation time $=60 \mathrm{~min})$. 
Table 3. Number of CHSU to be utilized in function of their diameter $D$.

\begin{tabular}{cc}
\hline Outer Diameter of CHSU [mm] & Number of CHSU [\#] \\
\hline 40 & 42 \\
52 & 33 \\
64 & 27 \\
76 & 22 \\
88 & 19 \\
100 & 17 \\
\hline
\end{tabular}

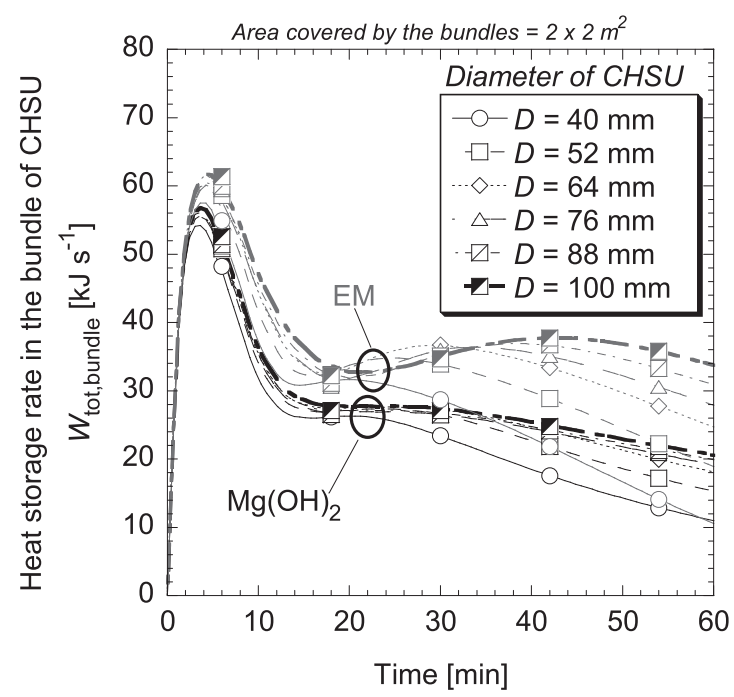

Fig. 11. Total heat storage rate in the CHSU bundles $W_{\text {tot, bundle }}[\mathrm{kJ}$ $\left.\mathrm{s}^{-1}\right]$ in function of their outside diameter, $D[\mathrm{~mm}]$. Results refer to $60 \mathrm{~min}$ of simulation, with $T_{\mathrm{ini}}=150^{\circ} \mathrm{C}$ and heat temperature of $400^{\circ} \mathrm{C}$.

$D$. A plateau is observed for value of $D$ within $64 \mathrm{~mm}$ and $76 \mathrm{~mm}$ : for these diameters, in fact, the contribution of chemical heat storage ratio $\Omega_{\mathrm{ch} \text {, bed }}$ decreased to $50 \%$ or becomes less, especially in case of bed of $\mathrm{Mg}(\mathrm{OH})_{2}$ pellets. The plot indicates that when $D=100 \mathrm{~mm}$, the CHSU bundle charged with EM tablets can store $141 \mathrm{MJ}$, while the CHSU bundle charged with $\mathrm{Mg}(\mathrm{OH})_{2}$ pellets can store $107 \mathrm{MJ}$. In one hour of operation, the system utilizing a CHSU bundle charged with EM tablets was capable to store $31.8 \%$ more heat in comparison with one charged with $\mathrm{Mg}(\mathrm{OH})_{2}$ pellets. On the other hand, larger $D_{\text {bundle }}$ decreases chemical heat storage performance which is useful for longer period storage.

In the last Fig. 11, the total heat storage rate $W_{\text {tot,bundle }}[\mathrm{kJ}$ $\mathrm{s}^{-1}$ ] is represented in function of the CHSU diameters. Its value is calculated at every time step $\Delta \tau$ for a single unit, then multiplied for the total number of CHSU in the bundle (as given on Table 3).

$$
W_{\text {tot bundle }}=\left.\frac{\left(Q_{\mathrm{s}, \text { bed }}+Q_{\text {ch,bed }}\right) \cdot V_{\text {bed }}+Q_{\text {s,steel }} \cdot V_{\text {steel }}}{\Delta \tau}\right|_{\tau=0 \rightarrow 60 \text { min }}
$$

The results indicates that the CHSU charged with EM tablets can store heat with a higher rate than the CHSU charged with $\mathrm{Mg}(\mathrm{OH})_{2}$ pellets. The plot show an initial peak related to the sensible heat necessary to reach the dehydration temperature. Then, a second peak is observed later, related to the heat chemical heat storage. Despite the different diameter and number of CHSU in the bundle, after 15 $\mathrm{min}$, the rate stabilizes around a constant value of 26 and 32 $\mathrm{kJ} \mathrm{s}^{-1}$ for CHSU charged with $\mathrm{Mg}(\mathrm{OH})_{2}$ pellets or EM tablets, respectively. From minute 20, the heat storage rate decreases for CHSU filled with $\mathrm{Mg}(\mathrm{OH})_{2}$ pellets, especially for the ones having smaller diameter. In case of CHSU charged with EM tablets, it is observed that the rate starts to increase again if the diameters $D>52 \mathrm{~mm}$, reaching a maximum within minute 50 . This is related to the better diffusion of heat into the core of the CHSU, similarly to what was already observed for the packed bed reactor experiments.

Optimization of $D$ would be still needed comprehensive discussion in the stand point of heat storage capacity, heat storage operation conditions and longer period heat storage capability.

\section{Conclusions}

Numerical model for thermochemical energy storage of dehydration operations for a bed of $\mathrm{Mg}(\mathrm{OH})_{2}$ pellets and a bed of piled EM tablets showed agreement with experimental results. In case of $\mathrm{Mg}(\mathrm{OH})_{2}$ bed, the dehydration advanced steadily in the proximity of the wall, which is the position close to the heat supply source. On the other hand, the results of EM bed indicated that heat could be transported rapidly through to the center of the bed. The temperature of the inner part of the bed rose faster because of the higher thermal conductivity. It was demonstrated that the EM composite tablets were more practical for a packed bed reactor than $\mathrm{Mg}(\mathrm{OH})_{2}$ pellets because of the higher thermal conductivity. Mold-ability of EM would make it possible to manufacture EM figures able to minimize the contact heat transfer resistance and further improve the thermochemical energy storage performance. A waste heat recovery system for steel industry was analyzed numerically. It was possible to determine the optimal diameter of CHSU in case of utilizing EM tablets or conventional $\mathrm{Mg}(\mathrm{OH})_{2}$ pellets as CHS material. The comparative analysis indicated that in one hour of operation, the larger diameter unit bundle has higher thermal storage capacity. The system utilizing a bundle of CHSU of $D$ of $100 \mathrm{~mm}$ charged with EM tablets would store $141 \mathrm{MJ}$ of heat, which is $31.8 \%$ higher than a bundle filled with $\mathrm{Mg}(\mathrm{OH})_{2}$ pellets. Similarly, the heat storage rate in CHSU bundles charged with EM tablets resulted higher than the ones charged with $\mathrm{Mg}(\mathrm{OH})_{2}$ pellets.

\section{Acknowledgment}

This study was executed with the financial support of the Grant-in-Aid for Scientific Research (B) \#24360404 from the Ministry of Education, Culture, Sports, Science and Technology (MEXT), Japan.

\section{Nomenclature}

$A$ side area node element

$\left(\mathrm{m}^{2}\right)$

$A_{0}$ frequency factor

$c$ specific heat capacity

CHSU chemical heat storage units

$D$ diameter

$E$ heat exchange term on boundaries of the packed 
bed

$E_{\text {a }}$ activation energy

$\left(\mathrm{J} \mathrm{mol}^{-1}\right)$

EG expended graphite

EM composite material of EG and $\mathrm{Mg}(\mathrm{OH})_{2}$

$k$ reaction rate constant

$M$ molecular mass

$\left(\mathrm{kg} \mathrm{mol}^{-1}\right)$

$m$ mass

$P$ pressure

$p$ pitch of CHSU

$Q$ total heat storage amount per unit volume

$\left(\mathrm{MJ} \mathrm{m}^{-3}\right)$

$R$ radius of packed bed reactor

$R_{\mathrm{g}}$ gas constant $\left(=8.314 \mathrm{~J} \mathrm{~mol}^{-1} \mathrm{~K}^{-1}\right)$

$r$ radial distance

$T$ temperature of node element

$\left(\mathrm{K}\right.$ or $\left.{ }^{\circ} \mathrm{C}\right)$

$T^{\circ}$ initial temperature of node element

$S$ total heat storage rate per unit volume

$s$ local heat storage rate per unit volume

$\left(\mathrm{kJ} \mathrm{s}^{-1} \mathrm{~m}^{-3}\right)$

$V$ volume of node element

$\left(\mathrm{kJ} \mathrm{s}^{-1} \mathrm{~m}^{-3}\right)$

$W$ total heat storage rate

$x$ reaction conversion

$\left(\mathrm{kJ} \mathrm{s}^{-1}\right)$

$Z$ height of the packed bed reactor

$z$ axial distance

' quantity calculated at time $\tau+\Delta \tau$

Greeks

$\alpha$ heat transfer coefficient

$\left(\mathrm{W} \mathrm{m}{ }^{-2} \mathrm{~K}^{-1}\right)$

$\Delta H^{\circ}$ standard enthalpy change of reaction $\left(\mathrm{kJ} \mathrm{mol}^{-1}\right)$

$\Delta m$ reactor's mass change

$\Delta \tau$ time step of calculations

$\Delta r$ size of node element, radial

$\Delta x$ reaction conversion change

$\Delta z$ size of node element, axial

$\lambda$ Effective thermal conductivity

$\Theta$ stored heat

$\left(\mathrm{W} \mathrm{m}^{-1} \mathrm{~K}^{-1}\right)$

$\rho$ density

(MJ)

$\tau$ time

$\left(\mathrm{kg} \mathrm{m}^{-3}\right)$

$\xi$ local concentration of $\mathrm{Mg}(\mathrm{OH})_{2}$

$\psi$ mass mixing ratio $\mathrm{Mg}(\mathrm{OH})_{2}$ : EG

$\Omega$ heat storage ratio

\section{Subscripts}

bed packed bed

bottom bottom position of the packed bed reactor bound boundary condition

bundle bundle of chemical heat storage units center central position of the packed bed reactor

ch chemical (heat)

cond condensation

d dehydration

end final value

$I$ total number of rows

$i$ index for rows

in inner position

ini initial value

$J$ total number of columns

$j$ index for columns

$\mathrm{MgO}$ magnesium oxide

$\mathrm{Mg}(\mathrm{OH})_{2}$ magnesium hydroxide

middle position at $R / 2, Z / 2$

out outer position

position position in the packed bed reactor

$r$ radial direction

reactor packed bed reactor

sens sensible (heat)

side side position of packed bed reactor

steel steel

top top position of the packed bed reactor

tot total

unit single chemical heat storage unit

wall wall of the packed bed reactor

$\mathrm{z}$ axial direction

\section{REFERENCES}

1) T. Kuroki, K. Kabeya, K. Makino, T. Kajihara, H. Kaibe, H. Hachiuma, H. Matsuno and A. Fujibayashi: J. Electro. Mater., 43 (2014), 2405.

2) F. Meng, L. Chen, F. Sun and B. Yang: Energy, 66 (2014), 965.

3) T. Nomura, N. Okinaka and T. Akiyama: Resour. Conserv. Recycl., 54 (2010), 1000 .

4) H. Zhang, H. Wang, X. Zhu, Y. Qiu, K. Li, R. Chen and Q. Liao: Appl. Energ., 112 (2013), 956.

5) Y. Kato, N. Yamashita and Y. Yoshizawa: Kagaku Kogaku Ronbunshu, 19 (1993), 1213.

6) Y. Kato, T. Saito, T. Soga, J. Ryu and Y. Yoshizawa: J. Chem. Eng. Jpn., 40 (2007), 1264.

7) Y. Takahashi, R. Sakamoto and M. Kamimoto: Int. J. Thermophys., 9 (1988), 1081.

8) M. Zamengo, J. Ryu and Y. Kato: Appl. Therm. Eng., 61 (2013), 853.

9) M. Zamengo, J. Ryu and Y. Kato: Appl. Therm. Eng., 64 (2014), 339.

10) Y. Kato, Y. Sasaki and Y. Yoshizawa: J. Chem. Eng. Jpn., 36 (2003), 833

11) S. V. Patankar: Numerical. Heat Transfer Fluid Flow, McGraw Hill, New York, (1980).

12) G. M. Zhabrova and V. A. Gordeeva: Kinetika i Kataliz, Akad. Nauk SSSR, (1960), 31.

13) P. J. Anderson and R. F. Horlock: Trans. Faraday Soc., 58 (1962), 1993.

14) R. S. Gordon and W. D. Kingery: J. Am. Ceram. Soc., 50 (1967), 8.

15) Y. Kato, M. Zamengo and K. Fujioka: Proc. 15th Int. Heat Transfer Conf. (IHTC-15), Begell House Inc, Connecticut, (2014), 9402. 